\title{
The External Forcing of the Atmospheric Response to a Sun-weather Relation
}

\author{
By Yukio Misumi* \\ Geophysical Institute Kyoto University, Kyoto, 606, Japan \\ (Manuscript received 25 July 1985, in revised form 4 November 1985)
}

\begin{abstract}
Variations of the solar surface and the interplanetary space that are responsible for the reported response in the lower atmosphere to the solar sector boundary (SSB) passages are discussed. Special attention is paid to elucidate the facts that the atmospheric response occurs 5 days before the SSB passages and is found only in the 8 winters from 1964 to 1972. The geomagnetic index $\mathrm{Kp}$ and the intensity of the galactic cosmic ray are used as the monitor of the corpusqular radiation and the $10.7 \mathrm{~cm}$ solar radio flux intensity is used as the monitor of $\mathrm{X}$-ray and EUV range intensity. The variation of the visible range is considered to be negligibly small.

Although the corpusqular radiation is closely related to the SSB passage, the starting day and the solar cycle dependence of its variation do not accord with those of the reported atmospheric response. The $10.7 \mathrm{~cm}$ flux does not have the physically controlled variation around the SSB passages. However, the $10.7 \mathrm{~cm}$ flux intensity had been accidentally and significantly weak during 8 days before the SSB passages in the 8 winters in the period from 1964 to 1972 . The period and the starting day of this variation is perfectly in accord with those of the reported atmospheric response.
\end{abstract}

\section{Introduction}

There are many reports about meteorological phenomena resulted by the solar variability (see Herman and Goldberg, 1978). However, most of them show only the statistical significance of the phenomena. For the purpose of establishing the existence of the sun-weather relation, the following three points should be clarified:

I. "internal response": The physical structure and behavior of meteorological phenomena.

II. "external forcing": The variation of the solar or interplanetary quantities correlating to the meteorological phenomena.

III. "linking process": The process linking I and II.

From this point of view, we reconsider an atmospheric response to the solar sector

* Present adress; Sendai District Meteorological Observatory, Gorin, Sendai, 983, Japan boundary (SSB) passage. In the first place, results about the "internal response" are summarized. Reports about the response of the vorticity area index (VAI) to the SSB passage (Wilcox et al., 1974, 1976; Hines and Halevy, 1977, etc.) did not discuss the interpretation of dynamics of the response or others using dynamically well-defined parameters (Williams, 1978; Williams and Gerety, 1980 ; etc) failed to find a response to the SSB passage. This point was criticized by Pittock and Shapiro (1982).

Recently, in order to make the "internal response" clear and dissolves this criticism, the present author (Misumi, 1981, 1983) found that the temperature in the polar troposphere and in the polar middle stratosphere responded to SSB passages. Furthermore, Misumi (1986) investigated the detailed feature of the dynamical process of the response in the lower atmosphere with the aid of the transformed 
Eulerian mean formulations system and found that responses; Wilcox et al. (1974), and Misumi (1981, 1983), are resulted by the decrease of the vertical energy flux of planetary waves with zonal wavenumber 2 and 3 in high latitudes in the troposphere. Consequently, three points remain to be explained:

[1-1]. The decrease of the vertical energy flux of planetary waves is not diagnosed by the TEM system and does not accompany with the variation of the wave energy.

[1-2]. This phenomenon begins about 5 days before the SSB passages.

[1-3]. This phenomenon is limited in 8 winters from 1964 to 1972 . Of course, this is common to other three responses mentioned (see Wilcox and Scherrer (1979), Arora and Padgaonkar (1981), and Misumi (1981, 1983)).

[1-1] must be explained by the "linking process". The "external forcing" should explain [1-2]. The change of the "external forcing" or that of the condition included in the "linking process", must be needed to explain [1-3].

Regarding the "external forcing", Wilcox (1979) mentioned that the SSB passage would provide only a convenient, precise time marker, and presumably the physical causes should be associated with other quantities that were organized in terms of the sector structure. Therefore, we reexamine variations of the Sun and the interplanetary space around the SSB passage from a viewpoint of their effects on the Earth as the possible "external forcing" in relation to [1-2] and [1-3].

\section{Background and data}

The solar activity is transmitted to the terrestrial domain by two ways; the corpusqular radiation and the electromagnetic radiation.

\subsection{Corpusqular radiation}

The corpusqular radiation is composed of the ionized particles (the solar wind) and the solar magnetic field frozen in them (the interplanetary magnetic field). Effects of the corpusqular radiation on the terrestrial domain are as follows:
Solar energetic particle (SEP): High energetic solar particles can intrude directly into the atmosphere. These particles are created by the burst of solar flares, which also accompanies the geomagnetic disturbances and X-ray and EUV spectra intensity enhancement. Its suddeness is inconsistent with the quasi-periodicity of SSB passages.

Geomagnetic disturbance (GD): The geomagnetic field is disturbed by the southward component of the interplanetary magnetic field which easily marges with the geomagnetic field and leads the interplanetary plasma into the magnetsphere. The GD is divided into two types; the geomagnetic storm caused by the burst of solar flares and the reccurent geomagnetic storm related to the solar rotation. The variation of $\mathrm{Kp}$, which is one of the geomagnetic indices around the SSB passage was regularly studied by Wilcox and Colburn (1969, 1970, 1972). They found that the geomagnetic field is disturbed just after the SSB passage and suggested that the reccurent geomagnetic storm occurred after the SSB passage. Hirshberg and Colburn (1973) reported that the reccurent geomagnetic storm is due to the reccurent high speed solar wind. The correlation between the reccurent high speed solar wind and the SSB passages is discussed in Appendix. The particle movement resulted or modulated by the GD are separated into the following two effects.

Relative electron precipitation (REP): Electrons in the outer radiation belt fall down into the middle atmosphere during GD. The amount of REP is directly connected to $\mathrm{Kp}$.

Galactic cosmic ray (GCR): The galactic cosmic ray intruding into the lower atmosphere is modulated by the geomagnetic field. The amount of GCR is measured by the neutron monitor counting rate at ground stations. In general, the amount of GCR has tendency to decrease (increase), when $\mathrm{Kp}$ increases (decreases). This tendency around SSB passages was reported by Wilcox and Ness (1965).

The particle precipitation, i. e., SEP, REP, and GCR, is reviewed by Thorne (1980) in detail. 


\subsection{Electromagnetic radiation}

The electromagnetic radiation is divided into three ranges from the viewpoint of their influence on the terrestrial domain. The first is the UV range that is absorbed mostly in the upper and middle atmosphere and controls the composition and ionization there. The second is the visible range that accounts for most of energy from the Sun and reaches directly the ground. The third is the radio range which has almost no influence on the atmosphere and of which some bands show good correlations with UV range. The time variation of the visible and UV range increases with decreasing its wavelength. Therefore, the X-ray and EUV range have the significant variation with the solar rotation period (Heath, 1973), though the visible range does not have.

Heath et al. (1975) (hereafter referred as $\mathrm{H} 75$ ) studied the variation of EUV radiation intensity around the SSB passages in the period of 1969-1972 by use of sensor A on Nimbus-3 and Nimbus-4 satellites which is sensitive to wavelengths near $121.6 \mathrm{~nm}$ (Heath, 1973). They found a significant variation that the EUV intensity has a maximum on Day -5 and minimum on Day 2 and considered that this variation results from the physical relation between the large-scale structure of EUV irradiance on the Sun and the solar magnetic field creating the solar sector structure. However, it seems that the analysis period is too short to accept this consideration.

The direct observation of the UV range intensity had not been performed so long as to cover the solar 11 year cycle period. Thus, the sunspot number or the solar radio flux, especially the $10.7 \mathrm{~cm}$ solar radio flux, are usually used as a monitor of the X-ray or EUV intensity, because both of them can be observed on the ground and have positive correlations with the X-ray and EUV intensity in both the solar 11 year cycle and the solar rotation period (Wende, 1969(a), (b)). It must be noted that the correlation coefficients between both of them and the EUV intensity are less than 0.5 (Heath, 1973). Therefore, they only show the tendency of the EUV intensity.

\subsection{Relationships between two types of radiation}

The correlation between the UV range radiation intensity and the corpusqular radiation in the solar rotation period was studied by use of the spectrum analysis (Misumi, 1981): The sunspot number and $10.7 \mathrm{~cm}$ solar radio flux intensity have a sharp spectral peak on the solar rotation period and $\mathrm{Kp}$ has separate peaks about that period. However, the cross spectrum between the sunspot number or $10.7 \mathrm{~cm}$ flux intensity and $\mathrm{Kp}$ has no peak on the period correlated to the solar rotation. These results indicate that: The lifetime of the solar active region where $\mathrm{X}$-ray and EUV radiation intensity is strong, is much longer than the solar rotation period (Heath and Wilcox, 1973). The lifetime of the source region of the high speed solar wind is longer than the solar rotation, but the position of the source region is under the modulation of the annual cycle (Wilcox and Scherrer, 1972). The positions of the active region are independent of those of the source region. Therefore, it is unlikely that there is a variation of the UV range radiation physically related to the SSB passages. ${ }^{* 1}$

For the "external forcing", the variations physically organized by the SSB are the most reasonable candidate. Furthermore, there is a possibility to observe a significant variation around the SSB passages peculiar to 19641972 , because the temporal structure of the solar surface is maintained much longer period than the solar rotation period. Although such type of variation has no meaning from the viewpoint of the solar or interplanetary science, such variation has the same chance to create the "internal response" in the limited period as the variation physically

\footnotetext{
*1 Propagation speeds of both radiations are quite different. Thus, the Earth is simultaneously affected by two different position of the Sun at a time. In the case of the reccurent type variation, the solar wind speed is crossly corelated to the GD, so the time relation of the GD and the elctromagnetic radiation can roughly transfer to the distance of the source region of them on the Sun. To say the least of it, the solar wind speed bringing the SSB is almost the same through the analysis period.
} 
organized by the SSB passages.

\section{$2.4 \quad$ Data}

As the index of the geomagnetic field, 12-hour averaged $\mathrm{Kp}$ is used. This data set covers the period from November 1964 to January 1979. The neutron monitor counting rate at Kiel, Mt. Norikura, and other observatories are used. The available period at Kiel is from September 1964 to December 1982 and at Mt. Norikura from January 1957 to December 1982 . The $10.7 \mathrm{~cm}$ solar radio flux intensity at Ottawa adjusted to 1 A.U. is used as the monitor of UV range radiation intensity, instead of the sunspot number, because the sunspot number merely indicates the sum of sunspots over the Sun's disk without the consideration of the position of them, but the $10.7 \mathrm{~cm}$ flux indicates the intensity of the radiation reaching the Earth. These three data are removed variations with periods longer than the 11 year cycle by use of the ormsby filter (Hasebe, 1980). Therefore, all results in this study are shown as deviations from the slowly varying field.

The SSB passages are those used in Misumi (1985) and those before 1964 chosen from Svalgaard (1976). The superposed method and others are the same as those of Misumi (1983, 1985).

\section{Results}

\subsection{Variations physically related with the SSB passage}

Fig. 1 shows (a) the variation of 12 -hour averaged $\mathrm{Kp}$, (b) that of the neutron monitor counting rate at Kiel, and (c) that of the $10.7 \mathrm{~cm}$ flux intensity around SSB passages. It is found from Fig. 1 that:

$(\mathrm{P}-1)$ The geomagnetic field is quiet just before and disturbed just after the SSB passage. Although other reports had insisted the disturbed condition, the quiet condition is more significant (see Appendix).

$(\mathrm{P}-2)$ The neutron monitor counting rate at Kiel has a maximum on Day $0^{* 2}$ and a minimum on Day 5. The same variation is

\footnotetext{
*2 Day $n(-n)$ represents $n$th day after (before)
} SSB passages.

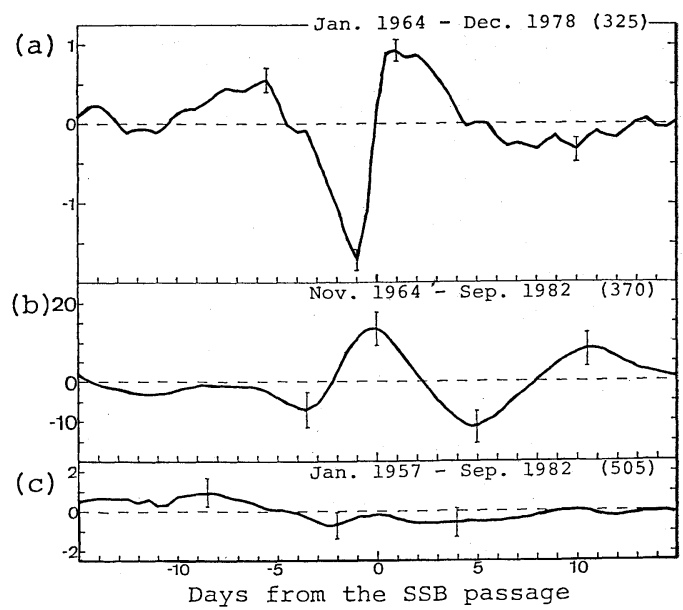

Fig. 1 Variation of 12 -hour averaged $\mathrm{Kp}$ (a), the neutron monitor counting rate at Kiel (b), and the $10.7 \mathrm{~cm}$ solar radio fiux intensity at Ottawa (c) around the SSB passages. The analysis period is indicated in the right side of each figure and the number of used SSB passages in the blanket. The vertical scale of (b) is counts per hour/300 and that of (c) is $10^{-22} \mathrm{~W} \mathrm{~m}^{-2} \mathrm{~Hz}^{-1}$.

also seen at other observatories. The maximum and minimum correspond to the quiet and disturbed geomagnetic field mentioned in $(\mathrm{P}-1)$, respectively, though their statistical significance is not so high as those of $(\mathrm{P}-1)$.

$(\mathrm{P}-3)$ There is no significant variation of the $10.7 \mathrm{~cm}$ flux intensity. It is considered that the physical relation supposed by $\mathrm{H} 75$ does not exist.

For the purpose of checking the solar cycle dependence of (P-1) and (P-2), Fig. 2(a) shows year-to-year change of averaged $\mathrm{Kp}$ on Day -1 and 1 , and (b) shows that of the neutron monitor counting rate at Mt. Norikura on Day 0. These variations have larger magnitude and are more significant in solar quiet years than in solar active years. This tendency accords the fact that the recurrent GD in the former is clearer than in the latter when many solar flares burst on the Sun.

\subsection{Variations accidentally occurring around the SSB passage}

Fig. 3 shows variations of the same parameters as Fig. 1, but confined to around the SSB passages in 8 winters from 1964 to 

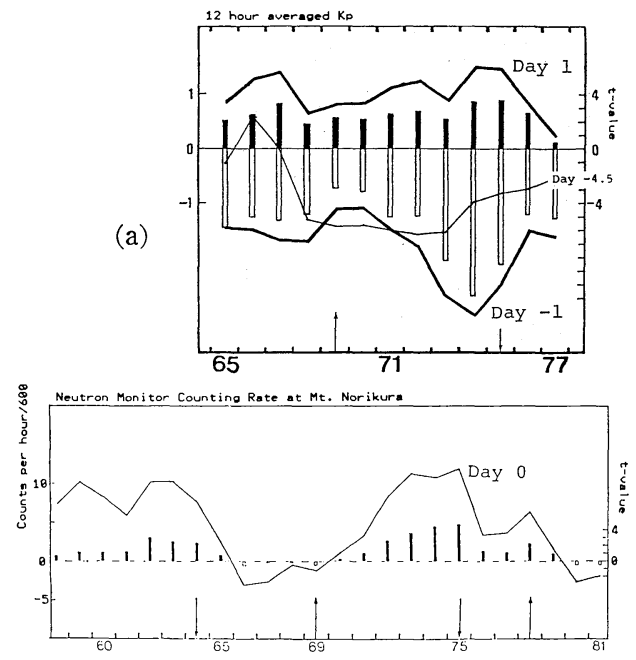

(b)

Fig. 2 (a) Variations of 12 -hour averaged $\mathrm{Kp}$ on Day 1 (above thick line) and Day -1 (below thick line). The thin line shows those on Day -4.5 in each two winters. (b) Variations of the neutron monitor counting rate at Mt. Norikura on Day 0 in each two years. Bars indicate Student's $t$ value of thick lines in each year. (The scale is indicated on the right side.) Upward (downward) arrows show the year of the sunspot maximum (minimum).

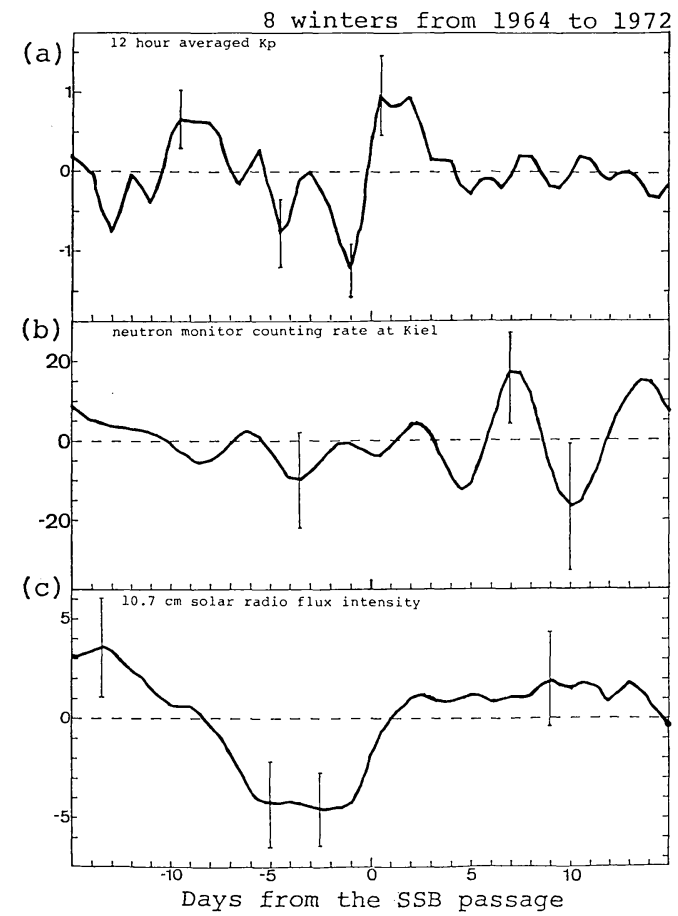

Fig. 3 The same as Fig. 1, but around 43 SSB passages in 8 winters from 1964 to 1972 .
1972 which are the same winters as [1-3]. This figure shows that:

(T-1) There are minima of 12-hour averaged $\mathrm{Kp}$ on Day -4.5 , in addition to the variation seen in Fig. 1(a).

(T-2) The neutron monitor counting rate has no significant variation in these winters, because $(\mathrm{P}-2)$ is not dominant in the solar active years as shown in Fig. 2(b).

(T-3) The $10.7 \mathrm{~cm}$ flux intensity is significantly weak between Day -8 and 0 . The same variation is also observed in the Zurich relative sunspot number.

In order to see the duration of the weak intensity of (T-3), Fig. 4 shows variations around SSB passages in each 3 winters from
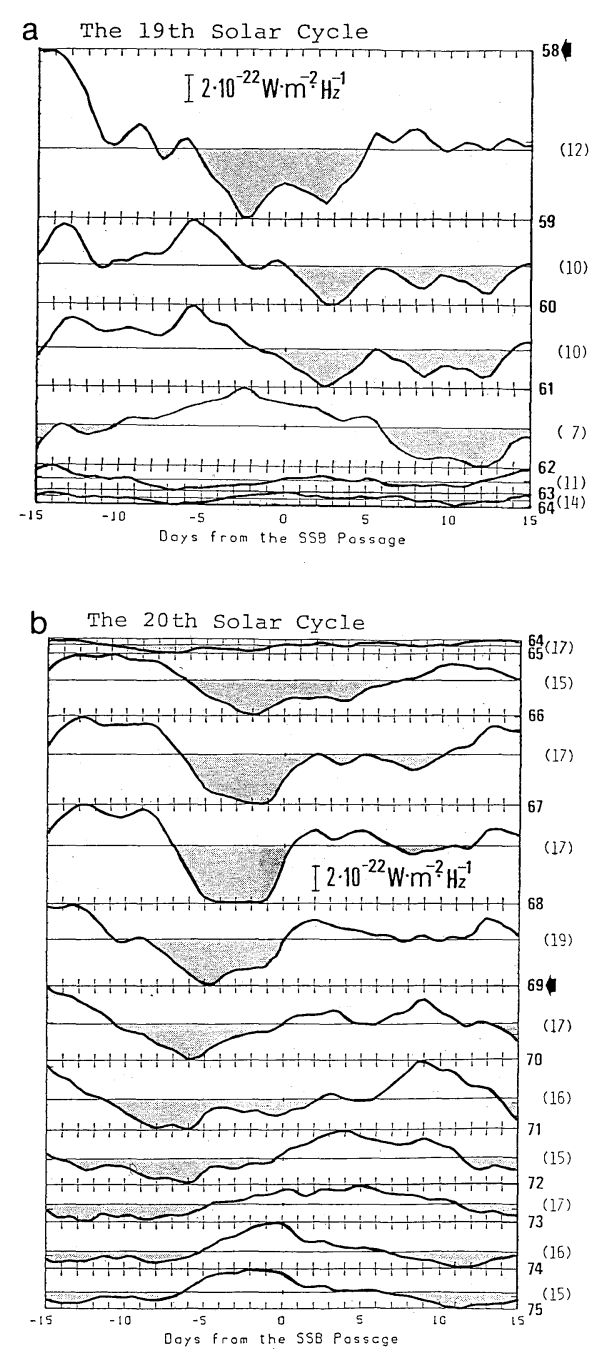
C

The 2lth Solar Cycle

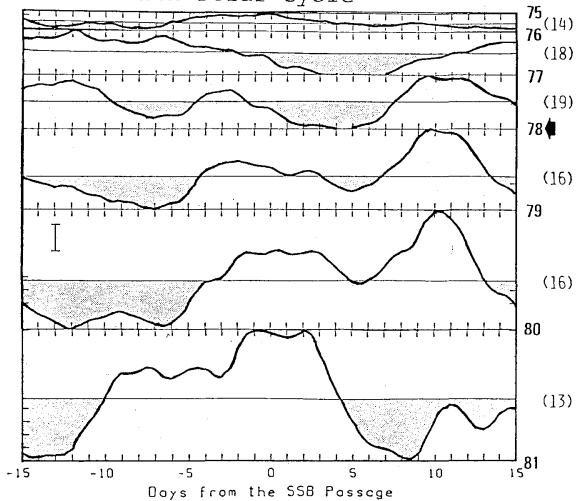

Fig. 4 Variations of the $10.7 \mathrm{~cm}$ solar radio flux around the SSB passages in each 3 winters centered the winter between the years indicated in the right above and below. The number of SSB passages is written in the right-center. The winters in the 19th, 20th 21 th solar cycle are shown separately in (a), (b), and (c). The years of the sunspot maximum are indicated by the thick arrows. The regions where the value is negative are hatched.

1957 to 1982 . It is seen that the magnitude of the variation with the solar rotation period is clearly controlled by the solar 11 years cycle: The magnitude becomes large during solar active years, when there are many active regions on the Sun. In addition to this, the weak intensity before the SSB passages is continuously seen in the solar active years in the 20th solar cycle, though the variation pattern in solar active years in 19 th or 21th solar cycle are entirely different. This indicates that the weak intensity before the SSB passages is the temporal variation occurring only in the 20th solar cycle. The averaged $\mathrm{Kp}$ on Day -4.5 in each year is shown in Fig. 2(a).

\subsection{Possibility as the "external forcing"}

The timing of $(\mathrm{P}-1)$ and $(\mathrm{P}-2)$ is too late to explain [1-2]. Moreover, as shown in Fig. 2, the amplitude of them is not dominant in the period of 1964-1972. On the other hand, the starting time of the weak radio flux $(\mathrm{T}-3)$ and that of the low $\mathrm{Kp}$ index around Day -4.5 ( $\mathrm{T}-1)$ seem to be early enough to be responsible for [1-2]. As shown in Fig. 4, the duration of $(\mathrm{T}-3)$ is in accord with [1-3]. However, this variation pattern of the $10.7 \mathrm{~cm}$ flux intensity is quite different from that of EUV intensity in H75. This difference is discussed in the next section.

\subsection{A comparison with Heath et al. (1975)}

The seasonal change of the $10.7 \mathrm{~cm}$ flux intensity variation pattern around the SSB passages in the period from 1964 to 1972 is shown in Fig. 5. The variation pattern similar to that of $\mathrm{H} 75$ is seen in months from August to October. On the other hand, the weak intensity before SSB passages is found in winter months and the similar pattern is seen in April and May. Even the months when ( $T-3)$ was seen, is in accord with that of the "internal response".

Such annual variation of the relation between the SSB passages and the $10.7 \mathrm{~cm}$ flux intensity is explained by the annual variation of the sector structure (see 2.3): The sector structure is decided by the solar magnetic field in a narrow latitudinal zone on the Sun facing to the Earth, which changes from the northernmost around 7th September to the southernmost around 7th March because of the inclination of the orbit of the Earth's revolution to the equatorial plane of the Sun. (see 2.3). On the other hand, the electromagnetic radiation to the Earth does not have such a large annual variation, because it is composed of the radiation from all over the solar disk. Thus, the position of the time marker, i.e. the SSB, on the variation pattern of the $10.7 \mathrm{~cm}$ flux changes with the annual cycle. The $\mathrm{H} 75$ pattern appears in the months from August to October when the northern polar region of the Sun is most tipped toward the Earth, and the pattern of Fig. 3(c) appears in both the months from December to February and the months from April to May when the similar zone in the solar southern hemisphere faces to the Earth.

\section{Discussion}

For the purpose of considering the "linking process", it is inconvenient that the variation of the UV range radiation affecting on the atmosphere is not measured directly. The variation of the $10.7 \mathrm{~cm}$ flux intensity shown 

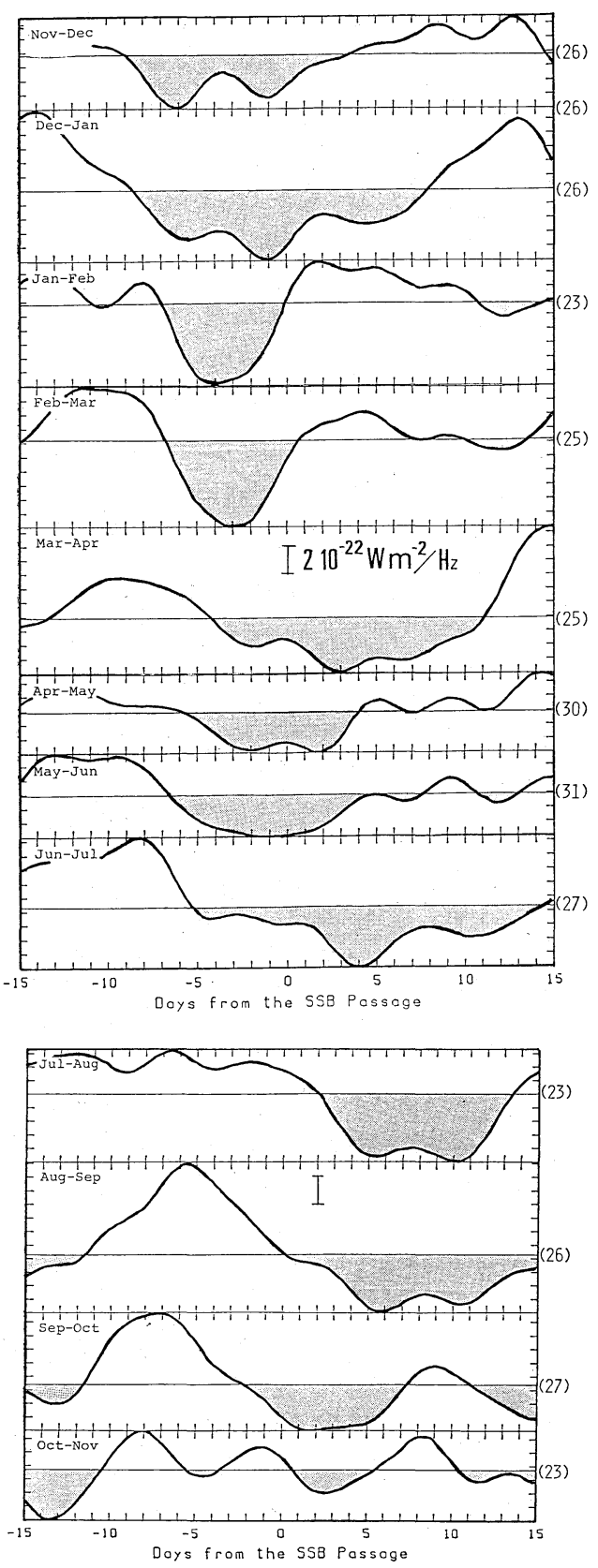

Fig. 5 Variations of the $10.7 \mathrm{~cm}$ solar radio flux intensity around the SSB passages in 2 months (indicated in the up-left) in the period from 1964 to 1972 . The number of the SSB passages analysed is written in the right side of each figure.

in Fig. 3(c) is about $10 \%$ of its averaged intensity. The variation of UV range intensity hidden in this variation is considered.
When it is assumed that the variation of the $10.7 \mathrm{~cm}$ flux is proportional to that of EUV intensity observed by H75, the magnitude of the variation of EUV spectra intensity corresponding to that of the $10.7 \mathrm{~cm}$ flux in Fig. 3(c) can be estimated by the comparison of the variation of the $10.7 \mathrm{~cm}$ flux intensity around the same SSB passages as those used in H75 and Fig. 1 in H75. This estimation indicates that the variation of $110-160 \mathrm{~nm}$ band intensity around the SSB passages is only $2-3 \%$ of its average intensity in the period from 1969 to 1972 .

This range is considered too small to produce the significant variation even in the middle atmosphere (Brasseur and Solomon, 1984). Moreover, when the key dates are defined by the dates in 8 winters of $1964-$ 1972 when the minimum of the $10.7 \mathrm{~cm}$ flux is observed in each solar rotation, we found no significant response of the temperature at the $500 \mathrm{mb}$ level at $90^{\circ} \mathrm{N}$ to these key dates (not shown) where the most significant response to the SSB passages is found (Misumi, 1983), though the variation of the $10.7 \mathrm{~cm}$ flux intensity around those key dates is about 5 times greater than that around the SSB passages.

Both the $10.7 \mathrm{~cm}$ flux intensity and $\mathrm{Kp}$ become significantly low values before the SSB passages in the 8 winters. As is shown in Fig. 6, this simultaneity is very characteristic on the condition of the non-relation between them. Both the effect by the electromagnetic radiation shorter than $120 \mathrm{~nm}$ and that by REP on the chemical constituents, ex. $\mathrm{NO}_{x}$, above the mesosphere, show the same tendency (Brasseur and Solomon, 1984). Therefore, if the variation of the electromagnetic radiation longer than $120 \mathrm{~nm}$ is negligibly small, the combination of these two effects remains to be an interesting candidate for the "linking process".

On the other hand, there is a possibility that very large variation of X-ray or EUV intensity is hidden in the variation of the $10.7 \mathrm{~cm}$ flux intensity shown in Fig. 3(c). In such a case, an interesting result was found by Misumi (1983) as follows: The temperature in the troposphere at the South Pole has 

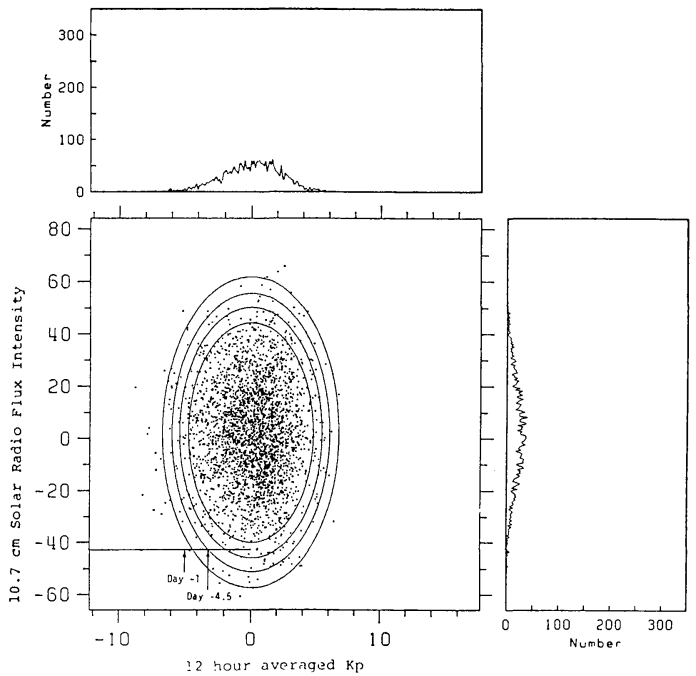

Fig. 6 Distribution of 3000 superposed results of the $10.7 \mathrm{~cm}$ solar radio flux intensity and 12 hour averaged $\mathrm{Kp}$. These superposition are performed by use of 43 key dates chosen randomly from 8 winters of 1964-1972 with more than 5 days intervals. 4 ellipses indicate $10 \%, 5 \%, 2.5 \%$ and $1 \%$ level of $\chi^{2}$ test respectively. The thin horizontal line indicates minimum in Fig. 3 (c), and the vertical arrows indicate the values of averaged $\mathrm{Kp}$ on Day -4.5 and -1 .

a maximum on 1.5 day after the SSB passages in the months from June to September (i. e., S. H. winter) of 1965-1971, before which the $10.7 \mathrm{~cm}$ flux intensity is significantly large (see Fig. 5). Although the temperature maximum is much less significant than the response in the N.H., the relation between the variation of the temperature and that of the $10.7 \mathrm{~cm}$ flux intensity is the same tendency with that of the response in the N. H.

\section{Conclusions}

(i) The variation of the $10.7 \mathrm{~cm}$ solar radio flux intensity suggests that UV range intensity had been accidentally and significantly weak during about 8 days before the SSB passages in the 8 winters of 1964-1972. The timing to the SSB passage and the duration of this variation is surprisingly convenient to express those of the atmospheric response to the SSB passages, ex. Misumi (1986).

(ii) The corpusqular radiation shows a significant variation physically controlled by the SSB. This variation can not explain those characteristics of the atmospheric response.

Although the supposed magnitude of EUV variation is found to be too small to bring about a significant variation even in the stratophere or the mesosphere, there remains a possibility that very large variation of X-ray or EUV intensity is hidden in the variation of the $10.7 \mathrm{~cm}$ flux intensity found around the SSB passages. Otherwise, the combination with the geomagnetic quiet condition is interesting as the candidate of the "linking process".

\section{Acknowledgements}

The author wishes to express his hearty thanks to Prof. I. Hirota of Geophysical Institute of Kyoto University for his continuous encouragement and critical reading of the manuscript. He also would like to thank superiors and colleagues of the Sendai District Meteorological Observatory for their encouragement and especially, Mr. Shirakawa for his help to print the manuscript. The computations were performed at the Data Processing Center of Kyoto University.

\section{Appendix}

It is supposed that the solar wind speed from a point on the solar surface depends on the distance from the magnetic neutral line on there, because the linking force of lines of the magnetic force restraining the solar plasma from running away, becomes its maximum near the magnetic neutral line. Therefore, the density and speed of the solar wind from the base of the SSB is a minimum. Such field becomes the slow and weak solar wind before the SSB passage near the Earth because of the modulation of the solar rotation. The low density solar wind is tied with the weak interplanetary magnetic field (IMF). Consequently, the southward component of the IMF should be weak before the SSB passage. Hence, the geomagnetic field becomes quiet just before the SSB passage. On the other hand, the high speed solar wind causing the reccurent geomagnetic storm (Hirshberg and Colburn, 1973) does not 
always blow after the SSB passages because the two dimensional structure of the magnetic neutral line on the solar surface affects on the distribution of the solar wind in the solar sector which is only a latitudinal section of that.

\section{References}

Arora, B. R. and A.D. Padgaonkar, 1981: Timevariation of solar influence on the tropospheric circulation. J. atmos. terr. Phys., 43, 91-95.

Brasseur, G. and S. Solomon, 1984: Aeronomy of the middle atmosphere. D. Reidel Publishing Company.

Hasebe, F., 1980: A global analysis of the fluctuation of the total ozone. II non-stationary annual oscillation, quasi-biennial oscillation, and long-term variations in total ozone. J. Meteor. Soc. Japan, 58, 104-117.

Heath, D.F., 1973: Space observations of the variability of solar irradiance in the near and far ultraviolet. J. Geophys. Res., 78, 2779-2792. and J.M. Wilcox, 1975: A possible correlation between maxima of the far ultraviolet and solar irradiance and central meridian passages of solar magnetic sector boundaries. Goddard Space Flight Center Special Report, NASA SP-366 (W. R. Bandeen and S.P. Maran, eds.), p 79-81.

- - L. Svalgarrd and T.L. Duvall, 1975: Relation of the observed far ultraviolet solar irradiance to the solar magnetic sector structure. Solar. Phys., 45, 79-82.

Herman, J. R. and R. A. Goldberg, 1978: Sun, Weather and Climate. NASA, SP-426, U. S. Gorvernment printing Office, Washington D.C.

Hines, C. O. and I. Halevy, 1977: On the reality and nature of a certain sun-weather correlation. J. Atmos. Sci. 34, 382-403.

Hirshberg, J. and D. S. Colburn, 1973: Geomagnetic activity at sector boundaries. J. Geophys. Res., 78, 3952-3957.

Misumi, Y., 1981: The response of the stratospheric temperature to the passage of solar sector boundaries. Paper presented at the meteorology and upper atmosphere. IAMAP Assembly, Hamburg, August, 1981.

- 1983: The tropospheric response to the possage of solar sector boundaries. J. Meteor. Soc. Japan, 61, 686-694.

- 1986 : A transformed Eulerian mean diagnostics for a sun-weather relation. J. Meteor Soc. Japan, 64, 125-137.

- and I. Hirota, 1983: Atmospheric variations around the passage of solar sector bound- aries in Antarctica (abstract). Proceedings of the fifth symposium on polar meteorology and glaciology, National Institute of Polar Reserch, November, 1983, p. 225.

Pittock, A. B. and R. Shapiro, 1982: Assessment of evidence of the effect of the solar variations on weather and climate. Solar variability, weather, and climate. National Academic Press.

Svalgaard, L., 1976: Interplanetary Sector Structure 1947-1975. Stanford University Institute for Plasma Research Report No. 648.

Thorne, R. M., 1980: The importance of energetic particle precipitation on the chemical composition of the middle atmosphere. Pageoph, 118, 128-151.

Wende, C.D., 1969 (a) : The correlation of solar microwave and soft X-ray radiation. 1. The solar cycle and slowly varying components. $J$. Geophys. Res., 74, 4649-4660.

— 1969 (b) : Correlation of solar microwave and soft $\mathrm{X}$-ray radiation. 2. The burst component. J. Geophys. Res., 74, 6471-6481.

Wilcox, J.M., 1979: Solar activity and changes in atmospheric circulation. J. atmos. terr. Phys., 41, 753-763.

— and N.F. Ness, 1965: Quasi-stationary corotating structure in the interplanetary medium. J. Geophys. Res., 70, 5793-5805.

- and D.S. Colburn, 1969: Interplanetary sector structure in the rising portion of the sunspot cycle. J. Geophys Res., 74, 2388-2392.

$\longrightarrow$ and -1970 : Interplanetary sector structure near the maximum of the Sunspot cycle. J. Geophys. Res., 75, 6366-6370.

- and — 1972: Interplanetary sector structure at solar maximum. J. Geophys. Res., 77, 751-756.

- and P.H. Scherrer, 1972: Annual and solar-magnetic-cycle variations in the interplanetary magnetic field. SUIPR Rpt. No. 466, Institute for Plasma Research, Stanford University, Stanford, Calif.

$\longrightarrow$ and $\longrightarrow, 1979$ : Variation with time of a Sun-weather effect. Nature, 280, 845-846.

- P.H. Scherrer, L. Svalgaard, W.O. Roberts, R.H. Olson and R.L. Jenne, 1974: Influence of solar magnetic sector structure on terrestrial atmospheric vorticity. J. Atmos. Sci., 31, 581588.

, L. Svalgaard and R.H. Scherrer, 1976 : On the reality of a Sun-weather effect. J. Atmos. Sci., 33, 1113-1116.

Williams, R.G., 1978: A study of the energetics of a particular sun-weather relation. Geophys. Res. Letts. 5, 519-522.

and E. J. Gerety, 1980: A further study of the tropospheric energetics of a paticular sunweather relation. J. atmos. terr. Phys., 42, 27-34. 


\title{
惑星間空間磁場境界通過に対する地球大気の応答の外部強制
}

\author{
三角幸 夫 \\ 京都大学理学部*
}

惑星間空間磁場境界通過時の粒子放射・電磁放射の変化を, 通過に対する大気の応答が 5 日前頃から始まり 1964 1972年間の冬に限られて起っていることに留意して調べた。粒子放射の変化は地磁気指数 Kp と宇宙線 量を用い X 線紫外線の変化は $10.7 \mathrm{~cm}$ の太陽電波を用いて調べた。可視光の变化は無視できるほど小さいと 考えている。

粒子放射は境界通過と密接な関係にあるが変化の始まる日や变化幅の年々变化は大気応答のそれらと違って いる。太陽電波は境界通過と物理的な関係はない。しかし，大気の応答と同じ期間には通過前 8 日間減少して いた。この期間の一致は非常に興味深い。

* 現在：仙台管区気象台 